\title{
Adverse Selection in Annuity Markets: Evidence from the British Life Annuity Act of 1808
}

\author{
Casey G. Rothschild*
}

January 28, 2009

\begin{abstract}
We study adverse selection using data from an 1808 Act of British Parliament that effectively opened a market for life annuities. Our analysis indicates significant selection effects. The evidence for adverse selection is strongest for a sub-sample of annuitants whose annuities were purchased by profit-seeking speculators, a sub-sample in which "advantageous selection" resulting from multi-dimensional heterogeneity is unlikely to have been significant. These results support the view that adverse selection can be masked by advantageous selection in empirical studies of standard insurance markets. JEL N23 D82.
\end{abstract}

* Middlebury College Economics Department, Middlebury, VT 05753. Tel: 802.443.5563. Email: crothsch@middlebury.edu. I thank James Poterba, Claudia Goldin, Jerry Hausman, Dora Costa, Peter Temin, Georges Dionne, Norma Coe, Robert Prasch, Raj Chetty and two anonymous referees for helpful comments. 


\section{Introduction}

In 1808, Britain's Parliament passed the Life Annuity Act, effectively opening a market for government-provided life annuities. The unique features of the Act provide an unusual opportunity to explore the empirical relevance of adverse selection.

Adverse selection has played an important role in economic theory since the seminal works of Akerlof (1970), Spence (1973), and others. Studying its empirical importance has proved challenging in several respects. First, as emphasized by Chiappori and Salanié (2000), it is difficult to distinguish empirically between moral hazard and adverse selection.

Second, researchers are unlikely to observe information hidden from insurers; this has motivated tests based on the correlation between insurance choices and ex-post risk, conditional on insurer-observed information. But these tests are still empirically problematic since econometricians often lack access to insurer-observed information.

Third, the existing empirical evidence for even the most theoretically robust consequences of informational asymmetries is surprisingly weak. For example, Cawley and Phillipson (1999) find no evidence of selection in life insurance markets, Cardon and Hendel (2001) find no evidence in health insurance markets, and Chiappori and Salanié (2000) and Dionne et al. (2001) find no evidence in auto insurance markets (in contrast to Pueltz and Snow (1994)). This absence of evidence may be due to insurance providers' countervailing informational advantages (Villeneuve, 2003) or else to a fourth empirical challenge: the confounding effects of "advantageous selection" resulting from, e.g., heterogeneity in risk aversion (DeMeza and Webb (2001), Cohen and Einav (2007), and Finkelstein and McGarry (2006)).

Annuity markets are a particularly interesting setting for studying informational asymmetries, not least because many of these challenges are less problematic. Moral hazard is plausibly negligible in annuity markets, and, since annuity providers typically do relatively little risk-classification, it is comparatively easy for researchers to observe the entire set of information employed by insurers in writing policies. Furthermore, highly risk averse individuals are likely both to be longer lived and to find longevity insurance more intrinsically appealing. Heterogeneity in risk aversion can thus be expected to reinforce rather than to mask the longevity-enhancing effects of adverse selection in annuity markets (Cutler et al. (2008)).

Finkelstein and Poterba's $(2002,2004,2006)$ studies of annuity markets 
have yielded some of the strongest empirical evidence of adverse selection, likely in part for these reasons. Unfortunately, the applicability and generality of their evidence is limited in at least two ways. First, it comes from a market where annuitization is mandatory. The substantial literature documenting a puzzling dearth of voluntary annuitization (Mitchell et al. (1999); Davidoff et al. (2005)) suggests caution in extrapolating from this evidence. Second, although advantageous selection due to heterogeneity in risk aversion is likely to reinforce rather than obscure adverse selection in annuity markets, the possibility of confounding advantageous selection arising from other dimensions of heterogeneity nevertheless remains a concern.

This paper uses the 1808 Act to provide a novel empirical look at adverse selection in the purely voluntary annuity market it effectively opened. We first provide evidence of adverse selection by showing that the annuitants were longer lived than age- and gender-specific population mortality tables would have suggested. Since annuity pricing under this Act varied only by age and gender, our evidence indicates selection relative to the risk-classification scheme employed by the U.K. government. We also document additional selection in response to an 1829 price increase designed to account for the enhanced longevity of early annuitants.

The most novel contribution of this paper stems from an odd feature of the 1808 Act that permitted "speculators" to purchase annuities on the lives of others. Selection by profit-seeking speculators was presumably based exclusively on longevity, thus mitigating concerns about the confounding effects of advantageous selection. In Section 5, we document that adverse selection was strongest among these speculator nominated annuitants. This supports the view that advantageous selection can significantly mask the empirical importance of adverse selection in standard insurance markets.

We describe the 1808 Life Annuity Act and its subsequent evolution in Section 2. Section 3 describes the available data, which are in an awkwardly condensed form that renders standard survival-curve analysis impossible. Section 4 presents some suggestive graphical evidence using "synthetic" survival curves and then develops a formal statistical test that we use in Section 5 to present our main results. Details of the formal test are contained in a brief technical appendix. Section 6 concludes. 


\section{The 1808 Act}

Prior to the Life Annuity Act of 1808, British government debt consisted almost exclusively of Consols - coupon bonds with infinite maturity. The explicit goal of the Act was to replace them with finite-lived debt by allowing individuals to exchange Consols for life annuities. ${ }^{1}$ Since Consols were tradable assets, the act effectively opened a life-annuity market.

Annuities sold under this act made twice-yearly tax-exempt payments. The size of these payments depended on the interest rate (the market Consol price) and the age of the annuitant (henceforth: the nominee). Prices were designed to be actuarially fair; to that end, they were priced to be $2 \%$ more expensive than the actuarially fair price implied by the Northampton life table. This table, first published by Richard Price in $1771,{ }^{2}$ was based on the mortality experience of all residents of the town of Northampton and was in wide use by life assurance companies (Francis, 1853).

Nominees had to be at least 35 years of age, and annuity yields were capped at age 75 , strongly discouraging purchases by older annuitants. A minister- or magistrate-certified register of birth or baptism was required for age verification. Similarly, verification of non-decease was required for receipt of each payment. Finally, the Act allowed individuals to "speculate on lives" by purchasing and owning annuities contingent on the lives of others. The nominee was required to be from Britain or Ireland for these purchases.

Shortly after passage of the Act, there appears to have been a recognition that the use of the Northampton tables was leading to large government losses. Murphy (1939) writes that it "was wholly unsuitable as a measure of the lower rates of mortality experienced by a self-selected group of annuitants. It was not long before this shortcoming was brought to the attention of the Exchequer." In contrast, Francis (1853) suggests that self-selection may have been a minor concern relative to speculation. He writes: "The speculators

\footnotetext{
${ }^{1}$ There may well have been more subtle motivations leading to its passage. Spencer Perseval, addressing Parliament in 1808 (viz Hendriks, 1856), argued that the Act would allow the government to retire debt at favorable interest rates without causing interest rates to rise - an argument Murphy ridicules as indicating Perseval's desire to "have his cake and eat it too" (Murphy, 1939, page 6) but which is plausible if the government believed it could extract surplus by filling a missing market. Alternatively, there could have been a political desire to align the interests of the retired monied classes with the government by providing them with a valued service - as argued by Weir (1989) for the French government-issued Tontines of the 18th century.

${ }^{2}$ We transcribed the tables from a republished version in Baily (1813).
} 
soon found out that the Government charge for a life annuity afforded a very remunerative investment, and the insurance offices made considerable profits by purchasing and re-selling them ... The mistake made by the Government in its calculations was no secret."

In 1823, Parliament finally took active steps to address this perceived mispricing by commissioning John Finlaison to study the mortality experience of the early nominees. ${ }^{3}$ His 1829 report developed a new set of gender-specific life tables (henceforth the "Finlaison tables") based on the observed mortality experience of these nominees. After some debate and a brief suspension of the life annuity program, Parliament determined to resume it with genderspecific pricing based on these new tables.

This re-pricing made annuities significantly more expensive: using pricing in Hendriks (1856) and a 3.75\% interest rate, we calculate, for example, that periodic payments fell by $4.4 \%$ and $17 \%$ for sixty year old males and females. Since the re-pricing was based on the longevity of the early annuitants and was designed to be actuarially fair, we infer significant government losses on early annuity sales, in spite of the $2 \%$ loading over the Northampton tables.

Ironically, the 1829 price increase appears to have coincided with a boom in "speculation," thanks to a contemporaneous decision to increase the maximum yield to age 90 . Because of the age 75 yield cap on early annuities, the old-age mortality experience underlying Finlaison's tables (hence new annuity prices) was primarily that of young nominees who subsequently grew old. John Francis (1853) relates a number of amusing anecdotes about speculators who, realizing that this would tend to cause Finlaison's tables to overstate the mortality of newly selected older lives, profitably combed the countryside for "hale and hardy" old men to nominate for annuities. ${ }^{4}$

To address this speculation, an 1834 law reduced the maximum yield to age 80 and effectively eliminated speculative purchases above age 65 (Murphy, 1939); speculation was then banned outright in 1852 (Cohen, 1953). The market for self-nominees continued, with periodic revisions to the life tables, until its dissolution under Parliament's 1962 Finance Act. Murphy (1939) suggests that these revisions prevented the government from experiencing significant losses after 1852 - perhaps in part because private companies entered the market offering better pricing. ${ }^{5}$

\footnotetext{
${ }^{3} \mathrm{He}$ also studied nominees of several earlier, smaller, life-contingent debt issues.

${ }^{4}$ Among these are tales of speculators paying surgeons and clergymen to maintain the health of the nominees - a rare case of moral hazard in annuity markets.

${ }^{5}$ See Parliamentary Papers (1808), Hendriks (1856), Murphy (1939), and The Insurance
} 


\section{Data}

Data are available from two Parliament-commissioned reports examining the profitability of the annuities sold under the 1808 Act. The first is John Finlaison's 1829 report, which contains data on annuities sold between 1808 and 1826. The second is his son Alexander Glen Finlaison's 1860 report, which examines annuities sold between 1808 and 1850 .

John Finlaison's 1829 report contains one data set for each gender. Each set consists of three columns of data. The first column is a list of the number of annuities sold between 1808 and 1826 at each nominee age. The second column lists the number of nominee deaths (between 1808 and January, 1826) at each age. The final column lists the ages of all "censored" nomineesi.e., those still living in January, 1826. We do not have individual level observations. Rather, all we observe are three distributions: an aggregate entry age distribution, an aggregate death age distribution, and an aggregate age-at-censoring distribution for the censored individuals.

The 1860 report has a similar format. It contains five distinct threecolumn data classes. The first three describe three distinct classes of "the nominees of those parties who speculated in life annuities" (A. G. Finlaison, 1860, p. 14), henceforth speculative nominees. All of these speculative nominees were males, and all were nominated after 1829. The first speculative data set contains 353 nominees aged 59 to 64 . The second contains 288 nominees aged 73-84. The third contains 34 nominees aged 85-92.

The final two data classes in A. G. Finlaison's report contain information on all male and female nominees from 1808 to the end of 1850, excluding the aforementioned speculative nominees, but including all nominees in John Finlaison's data. We refer to these nominee classes as "non-speculative" (but it is important to note that they may include speculative nominees from the 1808 and 1829 period as well as any post-1829 speculator-nominated annuitants that the government failed to identify as such).

The first data column in each of the five classes in the 1860 report lists the number of nominees at each age in that class. For the non-speculative males and females and the youngest speculative class, the second column lists the number of deaths, by age, for nominees who had died by May 8, 1854 . For the two older speculative classes, it also includes deaths between May 8, 1854 and June 10, 1856. The third column lists the number-by age on

Institute of London (1969) for additional historical details. 
Table 1: Complete Age 59-64 Speculative Nominee Data Set

\begin{tabular}{|c|ccc|c|ccc|}
\hline Age & $\begin{array}{c}\text { Number } \\
\text { Nominated }^{*}\end{array}$ & $\begin{array}{c}\text { Number } \\
\text { Dead }^{\dagger}\end{array}$ & $\begin{array}{c}\text { Number } \\
\text { Living }^{\ddagger}\end{array}$ & Age & $\begin{array}{c}\text { Number } \\
\text { Nominated }^{*}\end{array}$ & $\begin{array}{c}\text { Number } \\
\text { Dead }^{\dagger}\end{array}$ & $\begin{array}{c}\text { Number } \\
\text { Living }^{\ddagger}\end{array}$ \\
\hline 59 & 7 & 0 & 0 & 68 & 0 & 9 & 36 \\
60 & 50 & 0 & 4 & 69 & 0 & 5 & 43 \\
61 & 61 & 1 & 13 & 70 & 0 & 3 & 42 \\
62 & 91 & 3 & 25 & 71 & 0 & 1 & 22 \\
63 & 81 & 3 & 17 & 72 & 0 & 1 & 4 \\
64 & 63 & 7 & 17 & 73 & 0 & 0 & 7 \\
65 & 0 & 8 & 2 & 74 & 0 & 0 & 9 \\
66 & 0 & 6 & 16 & 75 & 0 & 0 & 4 \\
67 & 0 & 8 & 34 & 76 & 0 & 0 & 3 \\
\hline
\end{tabular}

*Between 1829 and 1850. †By May 8, 1854. †Nominees still living on May 8, 1854, by age on Dec 31, 1850. Source: A. G. Finlaison (1860).

December 31, 1850 - of nominees still alive on May 8, 1854 (June 10, 1856 for the two older speculative classes).

For illustrative purposes, Table 1 presents the entire data set for the youngest class of speculative nominees. The rest of the data are in a similar form; we omit them to save space.

Table 2 summarizes the data from the two reports. Of the 6892 annuities purchased between 1808 and January 1, 1826, we see that approximately $30 \%$ were male; $71 \%$ of male and $80 \%$ of female nominees were still alive on January 1, 1826. Of the 16137 non-speculative annuities purchased between 1808 and December 31, 1850, 34\% were male, and 41\% of each gender's nominees were still living on May 8, 1854. All of the older and all but one of the middle aged speculative nominees had died by June 10, $1856 .{ }^{6}$ Nearly $85 \%$ of the speculative nominees in the younger class were still living on May 8,1854 .

Since the 1860 non-speculative data set subsumes the 1829 data set, the increase in the (non-selected) male nominee proportion shown in Table 2 understates the true shift (to approximately 37.5\%) which occurred with the 1829 implementation of gender-specific pricing. Relatively more favorable pricing for men thus significantly shifted purchases in their direction, providing clear evidence of selection on observables.

\footnotetext{
${ }^{6} \mathrm{He}$ died at the age of 102 in March, 1857 (A. G. Finlaison, 1860, page 88).
} 
Table 2: Data Summary

\begin{tabular}{|c|c|cccc|}
\hline \multicolumn{2}{|c}{$\begin{array}{c}\text { Gender or } \\
\text { Class }\end{array}$} & $\begin{array}{c}\text { Nominees } \\
(\#)\end{array}$ & $\begin{array}{c}\text { Nominees } \\
(\%)\end{array}$ & $\begin{array}{c}\text { Dead } \\
\text { (\% of Row) }\end{array}$ & $\begin{array}{c}\text { Living } \\
\text { (\% of Row) }\end{array}$ \\
\hline 1829 & Male & 2077 & $30.1 \%$ & $28.6 \%$ & $71.4 \%$ \\
Report & Female & 4815 & $69.9 \%$ & $19.8 \%$ & $80.2 \%$ \\
\hline 1860 Report, & Male & 5542 & $34.3 \%$ & $59.3 \%$ & $40.7 \%$ \\
Non-Speculative & Female & 10595 & $65.7 \%$ & $58.9 \%$ & $41.1 \%$ \\
\hline 1860 Report, & Age 59-64 & 353 & $52.3 \%$ & $15.6 \%$ & $84.4 \%$ \\
Speculative & Age 73-84 & 288 & $42.7 \%$ & $99.7 \%$ & $0.3 \%$ \\
& Age 85-92 & 34 & $5.0 \%$ & $100 \%$ & $0 \%$ \\
\hline
\end{tabular}

The third (fourth) column reports the number (percent) of nominees. The fifth and sixth data columns report the percentage of nominees with in each class who were, respectively, dead and still-living at the time of observation (January 1, 1826 for the 1829 report; June 10, 1856 for the age 73-84 and 85-92 classes; May 8, 1854 for remainder of the 1860 report). Source: J. Finlaison (1829) and A. G. Finlaison (1860).

\section{Empirical Analysis}

Our basic empirical goal is simple: test for adverse selection by comparing the longevities of the various classes of nominees with their expected longevity, as predicted by an appropriate mortality table. The condensed form of the data poses a significant challenge, however. Note, for example, that each nominee in a given class implicitly appears twice: his age at nomination is recorded, and either his death age or his "censored" age is recorded. However, the data do not provide any way for us to connect these two appearances. This precludes us from using classic survival curve techniques.

We address this challenge in two ways. First, we show how the data can be used to generate "synthetic" survival curves for a given class of nominees; we present suggestive graphical evidence with these curves. Second, we describe a simple formal statistical test of whether the nominees in a given class were longer lived on average than a given mortality table would have predicted.

\subsection{Graphical Evidence: Synthetic Survival Curves}

The following technique can be used to estimate a mortality table for a given nominee class. ${ }^{7}$ Let the number $x_{t}$ of individuals "exposed" to death at age

\footnotetext{
${ }^{7}$ John Finlaison employed a similar technique to construct his tables.
} 
$t$ in a given class be defined recursively via

$$
x_{t}=x_{t-1}+e_{t}-d_{t-1}-l_{t},
$$

where $e_{t}$ denotes the number of age $t$ nominees in the data set (i.e., the firstcolumn, age $t$ entry), $d_{t}$ denotes the number of nominees who died at age $t$ (the second column entry), $l_{t}$ denotes the number individuals censored at age $t$ (the third-column entry), and $x_{t}=0$ for $t$ less than the age of the youngest nominee. ${ }^{8}$ Then the age $t$ mortality hazard $q_{t}$ is simply $\frac{d_{t}}{x_{t}}$.

We use this technique to generate five estimated mortality tables: one each for the 1808-1826 male and female nominees, one each for the 1808-1850 male and female nominees, and one for a data set which pools all three classes of speculative nominees. We then use these mortality tables to generate "synthetic" survival curves. ${ }^{9}$

Figure 1 plots four survival curves for age 45 females. The lowest curve plots the cumulative survival probability to age $t$, conditional on reaching age 45 , for an individual whose age $t$ mortality hazard is given by the Northampton table. The other three curves are analogous, but they instead assume mortality hazards given by the Finlaison (female) life table, and by life tables estimated using the above method with the 1808-1826 and 1808-1850 female nominee data sets. All three are approximately coincident and lie well above the Northampton survival curve. The 1808-1826 and 1808-1850 nominees thus appear to have had similar longevities, well above that of the

\footnotetext{
${ }^{8}$ This calculation implicitly assumes that individuals censored at age $t$ were not exposed at age $t$. The results are similar if we instead assume that individuals censored at age $t$ were fully exposed at age $t$. The "true" exposure - which we cannot observe given our datalies somewhere in between. We report only the present calculation since it overstates the estimated mortality rate and biases our graphical evidence away from demonstrating selection. An additional source of bias in the same direction stems from the fact that in the 1808-1850 data set the third column is the age on December 31, 1850 of all individuals who were still living as of May 8, 1854; we only partially incorporate this by aging the third column 3 years (i.e., we ignore the extra 5 months).

${ }^{9}$ It would be preferable to focus on the 1826-1850 nominees instead of the entire 18081850 nominees. We focus on the latter for two reasons. First, we cannot independently extract the mortality and censoring history of the later nominees from our data. For example, we can construct an age distribution of "late-dying" nominees by subtracting the second columns of the 1808-1826 data sets from the second columns of the 1808-1850 data sets. But this distribution combines deaths of post-1826 nominees with deaths of censored 1808-1826 nominees, and we cannot disentangle the two. Second, for related reasons, the formal statistical test we develop below focuses on the entire 1808-1850 nominee set, and it is useful to present graphical evidence which parallels this formal analysis.
} 


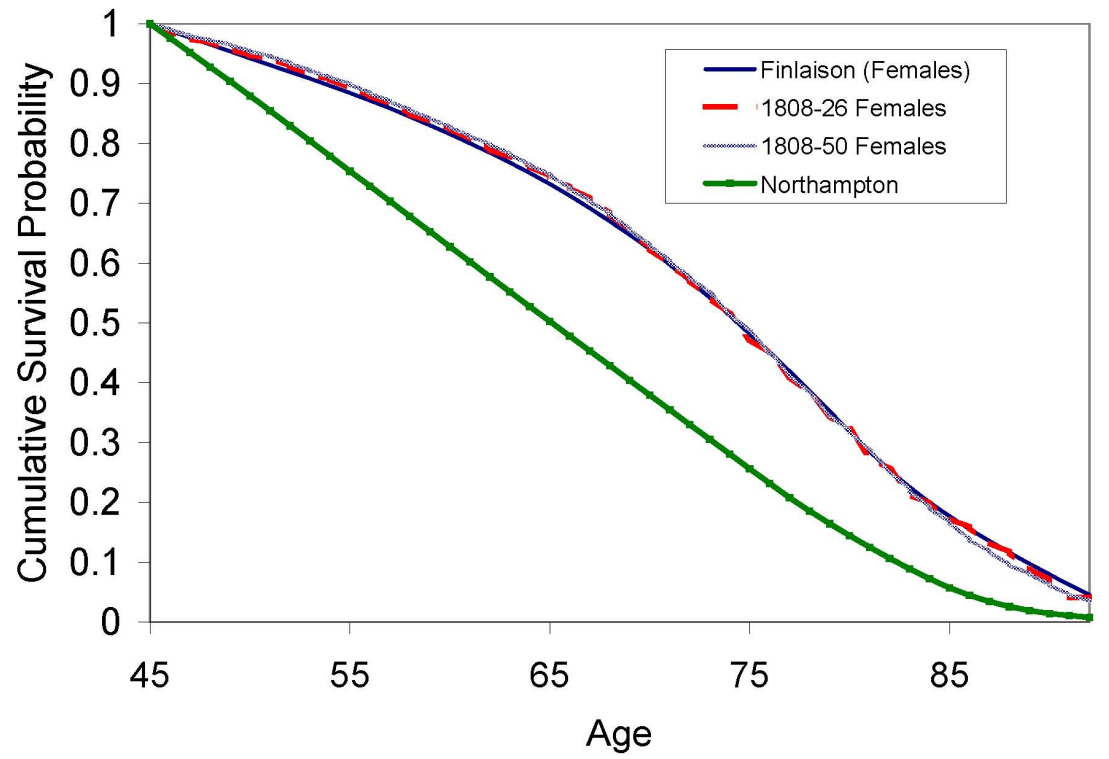

Figure 1: Female synthetic survival curves.

Northampton table and reasonably well approximated by Finlaison's table. In light of the comment in footnote 9, there is, if anything, mild evidence that the 1808-1850 female nominees were modestly longer lived than Finlaison's table would have predicted.

Figure 2 plots analogous curves for males. It includes a fifth survival curve based on the mortality table derived using the pooled speculative nominee data. It also plots the cumulative survival probabilities from age 59- the age of the youngest speculative nominees - rather than from age 45. Several features are striking. First, the 1808-1826 non-speculative nominees appear to have been longer lived than the Northampton table would have predicted. Second, the cumulative survival probabilities derived from the 1808-1826 nominee table and the Finlaison table do not perfectly coincide, ${ }^{10}$

\footnotetext{
${ }^{10}$ This is likely for two reasons. Finlaison included in his calculations the mortality
} 


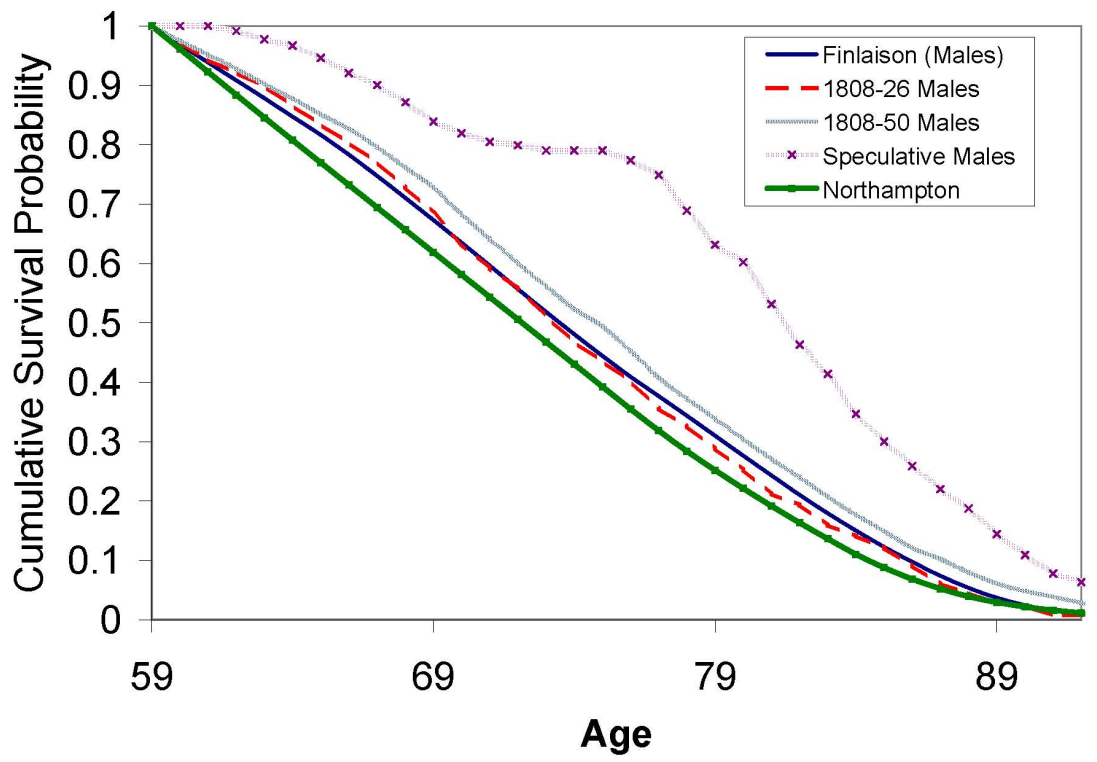

Figure 2: Male synthetic survival curves.

but they reflect roughly comparable longevities. Third, the 1808-1850 nominees appear to have been longer lived than the 1808-1826 nominees (and Finlaison's table). Finally, the speculative nominees were the longest lived class, apparently by a wide margin.

In summary, the graphical evidence suggests that early female nominees were selected relative to the Northampton table, while the later female nominees were, if anything, only mildly selected relative to Finlaison's table and the early nominees. Early male nominees were clearly selected relative to the Northampton table, and later male nominees were significantly selected relative to the early nominees and Finlaison's table. Finally, the speculative nominees were strongly selected relative to everyone else. These qualitative

experiences of the nominees from earlier life-contingent debt issues in Britain and Ireland, and he seems to have done some "smoothing" across several ages in developing his table. 
conclusions are all borne out by the formal statistical test we now develop.

\subsection{A Formal Statistical Test}

Toward developing a formal statistical test for selection using our data, we first describe a simple statistical test that applies when we know the death ages of all nominees. We then show how to extend it to account for censoring.

Take as given a population mortality table $\vec{q}=\left(q_{0}, q_{1}, q_{2}, \cdots, q_{109}, q_{110}\right)$, where $q_{t}$ denotes the age- $t$ mortality hazard, and where we assume that nobody survives beyond age 110. View the first column of data from each nominee class as a known vector $\vec{e}=\left(e_{0}, e_{1}, \cdots, e_{109}, e_{110}\right)$, where $e_{t}$ is the number of age $t$ nominees. Let $\bar{d}$ denote the realized value of the (random) average death age of the nominees. If $\vec{q}$ correctly captures the mortality of the nominees $\vec{e}$, then the test statistic

$$
Z=\frac{\bar{d}-E[\bar{d} \mid \vec{e}, \vec{q}]}{\sqrt{V[\bar{d} \mid \vec{e}, \vec{q}]}},
$$

has an asymptotic standard normal distribution, where $E[\vec{d} \mid \vec{e}, \vec{q}]$ and $V[\bar{d} \mid \vec{e}, \vec{q}]$ are, respectively, the expected value and the variance of $\bar{d}$ (given $\vec{q}$ and the observed $\vec{e}$ ). High $Z$ scores are then evidence of a nominee pool that is adversely selected relative to $\vec{q}$.

For data sets with censoring, the realized value of $\bar{d}$ is unknown, and Equation (2) cannot be used. Towards developing an analogous test which applies with censoring, consider Figure 3, which illustrates how we implement the statistical test based on Equation (2) for the oldest class of speculative nominees and with $\vec{q}$ given by Finlaison's table. It shows three distributions: the age distribution of the nominees; the distribution of the final death ages of these nominees (which are fully known for this class); and the death age distribution that would be expected if the nominees aged according to Finlaison's tables. The last of these is computed by averaging over a large number - 8000, in practice - of simulated death age distributions. Each of these 8000 trials is generated by using Finlaison's tables to randomly draw a final death age for each nominee.

Equation (2) is simply a test of whether the actual distribution of death ages has a statistically significantly higher mean than the expected death age distribution. For the oldest speculative nominees, it simply tests formally 


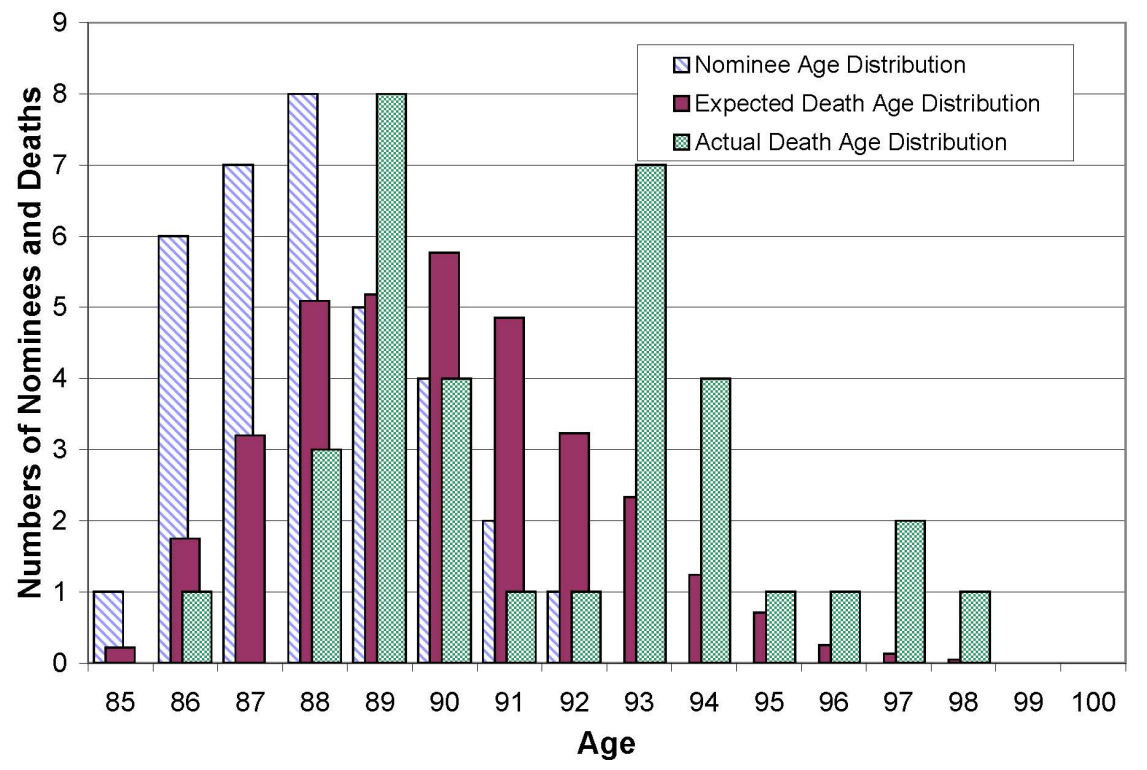

Figure 3: Expected and actual death age distributions for the oldest class of speculator nominated annuitants.

whether the mean of the actual death age distribution in Figure 3 is rightshifted relative to the mean of the expected death age distribution. We estimate the variance of the latter (for the denominator in Equation (2)) with variance of the average death ages generated in the 8000 trials.

Figure 4 contains an analogous plot for the youngest class of speculative nominees - most of whom are censored. It depicts two distributions. The first, labeled "Unconditionally Expected Death Age Distribution" is the exact analog of the "Expected Death Age Distribution" in Figure 3. It is an average of 8000 simulated death age distribution trials, each of which uses Finlaison's tables to randomly draw a final death age for each nominee.

We do not observe the final death age distribution of the youngest speculative nominees, so there is no exact analog of Figure 3's "Actual Death Age Distribution" in Figure 4. Instead, we observe the death age distribu- 
tion of the non-censored nominees, and the age-at-censoring distribution of the others. We use these two distributions to generate the "Conditionally Expected Death Age Distribution" in Figure 4. This is the death age distribution one would expect when given the list of the censored ages and a list of the ages of the already-dead individuals, under the assumption that the censored individuals would subsequently age according to Finlaison's table. We compute this distribution by again averaging over 8000 simulated death age distribution trials. In each trial, we first use Finlaison's table to randomly draw a final death age for each censored individual, and we then add the resulting distribution of censored-individual death ages to the known death age distribution of the non-censored individuals.

Our test for selection in the presence of censoring, formalized in Equation (3) below, is a test of whether the mean of the conditionally expected death age distribution $\left(E\left[\vec{d} \mid \vec{l}, \overrightarrow{d^{\text {early }}}, \vec{q}\right]\right)$ is higher than the mean of the unconditionally expected death age distribution $(E[\bar{d} \mid \vec{e}, \vec{q}])$. In other words, is the former distribution right shifted relative to the latter, as it appears to be in Figure 4 for the youngest speculative nominee class?

A formal test requires deriving an estimate of the asymptotic variance of the difference between the unconditional and conditional mean death ages. This is more difficult than in the no-censoring case, since the conditional mean death age and the unconditional mean death age are not independent variables. In the Appendix, we show that the appropriate variance to use is simply the difference in the variances of the conditional and unconditional mean death ages. Formally, we show that:

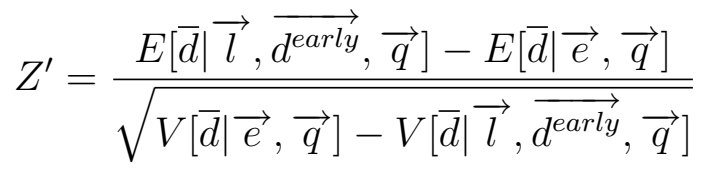

has an asymptotic standard normal distribution (under the hypothesis that the mortality of the nominees is correctly described by mortality table $\vec{q}$ ). $Z^{\prime}$ thus serves as the basis for our formal statistical test for selection among classes with censoring. ${ }^{11}$

A high $Z^{\prime}$ provides evidence of an adversely selected set of nominees. Note, however, that the numerator in Equation (3) likely underestimates the degree of adverse selection since $E\left[\bar{d} \mid \vec{l}, \overrightarrow{d^{\text {early }}}, \vec{q}\right]$ is computed under the

\footnotetext{
${ }^{11}$ We again use the 8000 trials to estimate $V[\bar{d} \mid \vec{e}, \vec{q}]$ and $V\left[\bar{d} \mid \vec{l}, \overrightarrow{d^{\text {early }}}, \vec{q}\right]$.
} 


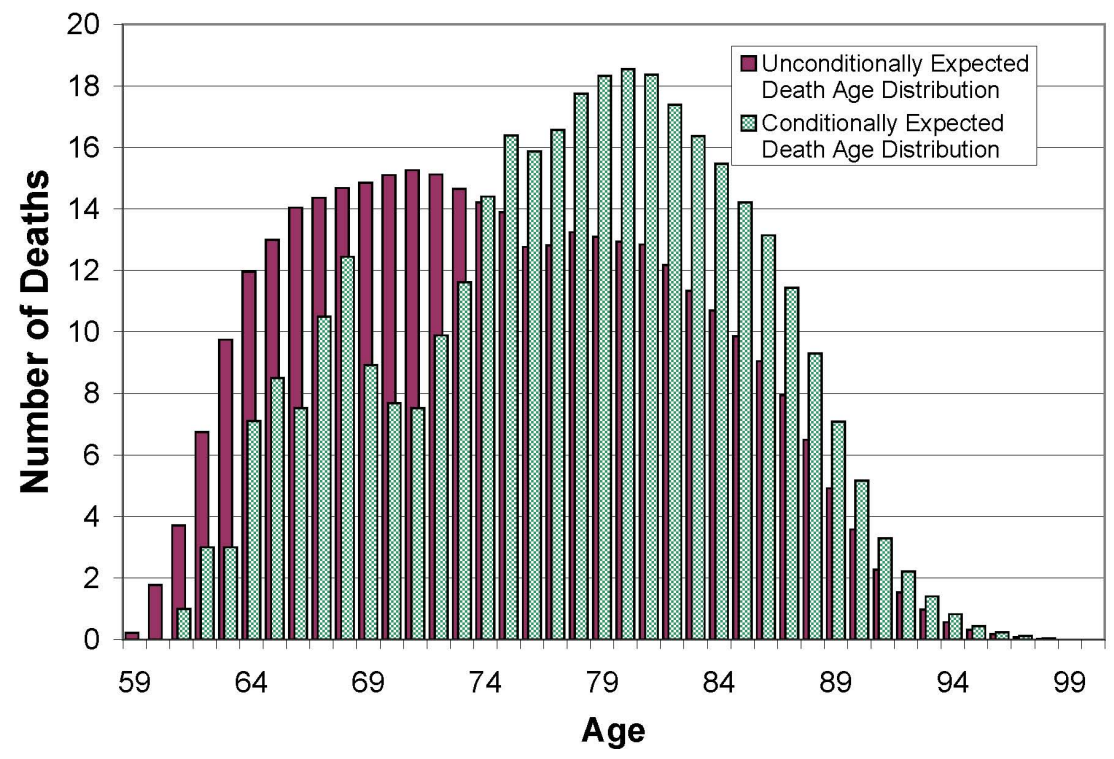

Figure 4: Unconditionally and conditionally expected death age distributions for the youngest class of speculator nominated annuitants.

assumption that the censored individuals subsequently aged according to the non-selected mortality table.

\section{$5 \quad$ Results}

We first present the basic results of tests based on Equations (2) and (3). These tests confirm the selection patterns suggested by Figures 1 and 2. We then briefly discuss and dismiss two potential caveats: the possible inappropriateness of Northampton table as a population mortality table, and the potentially confounding effects of time trends. Finally, we quantify the size of the selection effects among the various classes. 
Table 3: Testing for Adverse Selection, Northampton Tables

\begin{tabular}{|c|c|c|c|c|}
\hline & \multicolumn{2}{|c|}{$E(\bar{d})$} & $\hat{\sigma}$ & $Z^{\prime}$ \\
\hline & Unconditional & Conditional & & \\
\hline Males, 1826 & 72.34 & 72.97 & 0.126 & 5.02 \\
\hline Females, 1826 & 71.31 & 72.84 & 0.082 & 18.72 \\
\hline
\end{tabular}

$E(\bar{d})$ refers to the expected average nominee death age of all nominees. Column "Unconditional" ("Conditional") reports the unconditional expected average death age (the expected average death age conditional on the observed mortality history through 1826). Column $\hat{\sigma}$ is the estimated standard error of the difference between these two columns. $Z^{\prime}$ is the $Z$-score of the difference (viz Equation (3)).

\subsection{Basic Statistical Results}

Table 3 uses Equation (3) to test the appropriateness of the Northampton tables for the male and female nominees in the 1829 data set. It indicates that the early nominees of both genders were conditionally predicted to live significantly longer than they were unconditionally predicted to live, with males and females conditionally estimated to live an average of .63 (i.e., $72.97-72.34$ ) and 1.53 years longer, respectively. As discussed above, these differences likely understate the degree of selection.

Table 4 uses Equations (2) and (3) to test the appropriateness of Finlaison's tables for each of the seven nominee classes. The final two rows indicate that Finlaison's life tables were appropriate for the 1808-1826 nominees: the conditionally and unconditionally expected average death ages are statistically identical for both males and females.

The first two rows of Table 4 indicate that for the 1808-1850 non-speculative nominees, the conditionally predicted longevity exceeds the unconditionally predicted longevity by 0.84 and 0.22 years for males and females, respectively. Both are statistically significant at standard levels. ${ }^{12}$

Finally, the middle 3 rows of Table 4 indicate that all three speculative nominee classes had significantly greater longevity than Finlaison's tables predicted.

\footnotetext{
${ }^{12}$ The pre-1826 nominees are a subset of these nominees. Hence, this is a pure test for additional selection amongst post-1826 nominees only insofar as the Finlaison tables accurately describe the mortality of early nominees.
} 
Table 4: Testing for Adverse Selection, Finlaison Tables

\begin{tabular}{|c|c|c|c|c|}
\hline & \multicolumn{2}{|c|}{$E(d)$} & \multirow[t]{2}{*}{$\hat{\sigma}$} & \multirow[t]{2}{*}{$Z, Z^{\prime}$} \\
\hline & $\underline{\text { Unconditional }}$ & $\underline{\text { Conditional }}$ & & \\
\hline NS Males, 1850 & 73.79 & 74.63 & 0.126 & 7.81 \\
\hline NS Females, 1850 & 76.23 & 76.45 & 0.087 & 2.56 \\
\hline S Males, 59-64 & 74.84 & 77.72 & 0.320 & 9.01 \\
\hline S Males, 73-84 & 83.40 & 84.72 & 0.230 & 5.10 \\
\hline S Males, $85+$ & 89.88 & 91.62 & 0.329 & 5.28 \\
\hline Males, 1826 & 73.87 & 73.87 & 0.123 & -0.05 \\
\hline Females, 1826 & 76.12 & 76.11 & 0.086 & -0.17 \\
\hline
\end{tabular}

"NS" and "S" refer to non-speculative and speculative classes, respectively. $E(\bar{d})$ refers to the expected average death age of all nominees. Column "Unconditional" ("Conditional") reports the unconditional expected average death age (expected average death age conditional on the observed mortality history through 1854, 1856, or 1826 for the first four rows, the fifth row, and the final two rows, respectively). Column $\hat{\sigma}$ is the estimated standard error of the difference between the two death age estimates. $Z, Z^{\prime}$ is the $Z$-score of the difference between the conditional and unconditional average death ages (viz Equations (2) and (3)).

\subsection{Selection Among 1808-1826 Nominees}

Under the 1808 Act, Parliament priced annuities under the assumption that the Northampton tables described the mortality of the British population. The results in Table 3 indicate either that there was significant selection amongst the early nominees or that Parliament's assumption was incorrect.

The Northampton table was based on the mortality history of residents in a single town, and it was developed from observations in the mid 1700s, so its appropriateness as a measure of population-average mortality in the early 1800 s is clearly suspect. Unfortunately, reliable data on mortality rates prior to 1838 - when the British Government began systematically recording all births and deaths - are lacking (McKeown and Record, 1962). The earliest reliable population mortality table, known as the English Life Table 3 (ELT3), was developed by William Farr using data collected between 1838 and 1853 (Farr, 1864). Table 5 compares the magnitudes of the selection effects relative to the Northampton, Finlaison, and ELT3 tables. It indicates significant selection effects among early nominees even relative to ELT3 (albeit more modest ones than relative to the Northampton table). This suggests that, while the Northampton tables may have been inappro- 
Table 5: Comparing Selection Effects Across Life Tables

\begin{tabular}{|l|rr|rr|rr|}
\hline & \multicolumn{6}{|c|}{ Excess Years Lived (Z-score) } \\
Class & \multicolumn{2}{|c|}{ Northampton } & \multicolumn{2}{|c|}{ Finlaison } & \multicolumn{2}{|c|}{ ELT3 } \\
Males, 1826 & 0.63 & $(5.0)$ & 0.00 & $(0.0)$ & 0.35 & $(2.9)$ \\
Females, 1826 & 1.53 & $(18.7)$ & -0.01 & $(-0.2)$ & 0.91 & $(11.6)$ \\
NS Males, 1850 & 2.24 & $(20.9)$ & 0.84 & $(7.8)$ & 2.00 & $(14.4)$ \\
NS Females, 1850 & 3.90 & $(46.9)$ & 0.22 & $(2.6)$ & 2.51 & $(30.2)$ \\
\hline
\end{tabular}

This table reports the difference between the conditional and unconditional expected number of years lived for three life tables (the Northampton, Finlaison, and English Life Table 3 described in the text) and four nominee classes. Parentheses denote Z-scores (viz Equation (3)).

priate, selection effects were nevertheless important.

\subsection{Self-Selection Among Subsequent Nominees}

Table 4 indicates that the Finlaison tables did a good job capturing the mortality of the early nominees but overstated the mortality of the late nominees. To interpret this as evidence of additional selection subsequent to the 1829 re-pricing, we need to rule out a time trend in mortality rates. The lack of reliable data prior to 1838 prevents us from doing so fully definitively, but time trends seems likely to have been of negligible importance over our period of study.

Wrigley and Schofield (1981, pages $230 \mathrm{ff}$ ) indicate that life expectancy at birth exhibited a mild upward trend between 1800 and 1850, but Greenwood (1936), examining post-1841 data, suggests that this trend was driven exclusively by early-life mortality, stating:

When the historical sequence is examined... [O]ne could hardly say that the rate at 35-45 had moved decisively before the early eighties, or that at ages 45-55 until the turn of the century. In old age, improvement is now barely perceptible. (Page 678.)

The post-1841 age-specific mortality trends plotted in McKeown and Record (1962) strongly support Greenwood's claims and give us confidence that the increased longevity of the later nominees is primarily attributable to additional selection.

This pattern - selection, repricing, and then additional selection - is reminiscent of the first stages of an Akerlovian death spiral (as found by Cutler 
and Reber (1998) but not Buchmueller and DiNardo (2002) in health insurance contexts). The spiral was clearly incomplete in 1850 - additional rounds of re-pricing and market thinning were needed - and the lack of data going forward prevents us from definitively determining whether or not the market would have completely unraveled. However, the magnitudes of the shift in market size and longevity among females suggest that the market would not have been eviscerated by a death spiral. Indeed, the average annual sales to female nominees fell quite modestly (by about 10\%) in response to the substantial (approximately 17\%) 1829 re-pricing, and the later nominees were only modestly longer-lived than the early nominees. A back-of-the-envelope extrapolation of the demand and pricing responses from the first round of re-pricing suggests that all further rounds of the spiral would have thinned the market by only an additional 5 to $20 \%$. $^{13,14}$

\subsection{Comparing the Degrees of Selection}

Table 4 shows that the speculative and the non-speculative nominees from A. G. Finlaison's data set both displayed higher longevity than Finlaison's table predicted. Figures 1 and 2 qualitatively suggest that the speculative nominees were significantly longer-lived than the non-speculative nominees. To affirm this, we compute "longevity enhancement factors" (LEFs), which quantify the degree of selection, for each nominee class. LEF is defined as:

$$
L E F=\frac{\text { Actual average death age }- \text { Expected average death age }}{\text { Expected average death age - Average nomination age }},
$$

i.e., the percent by which average longevity exceeded predicted longevity.

A direct computation of a LEF is impossible when there is censoring, so we instead compute upper and lower bounds. Our lower bound assumes that the still-living nominees subsequently aged according to Finlaison's tables.

\footnotetext{
${ }^{13}$ The lower end is based on the $10 \%$ per-annum quantity response by females (Table 2 ) to the $17 \%$ re-pricing, and the roughly $4 \%$ longevity increase of the later nominees (using Table 6 , below, and the fact that about half of the nominees in the later data set were "unselected" early nominees). The upper end is based on a similar calculation instead using a "differences in differences" approach relative to males.

${ }^{14}$ Murphy (1939) indicates that the market stabilized and gradually shrunk after speculation was banned in 1852. One must interpret this cautiously, however (and not only because we lack data): by the late 1800s, the confounding effects of improving mortality trends begin to bite, and, furthermore, private-sector annuities became viable alternatives.
} 
Table 6: Estimated Longevity Enhancements

\begin{tabular}{|c|c|c|}
\hline Class & Lower Bound LEF & Upper Bound LEF \\
\hline Non-Speculative Males, 1850 & $5.65 \%$ & $9.06 \%$ \\
\hline Non-Speculative Females, 1850 & $1.17 \%$ & $1.80 \%$ \\
\hline Speculative Males, 59-64 & $22.56 \%$ & $121.91 \%$ \\
\hline & \multicolumn{2}{|c|}{ Exact LEF } \\
\hline Speculative Males, 73-84 & \multicolumn{2}{|c|}{$25.37 \%$} \\
\hline Speculative Males, $85+$ & \multicolumn{2}{|c|}{$94.02 \%$} \\
\hline
\end{tabular}

Estimated "longevity enhancement factors" (LEF): the percentage by which the longevity of a given group of nominees exceeded the longevity predicted by Finlaison's mortality tables.

Our upper bound assumes instead that the still-living nominees had equal enhancement factors prior to and subsequent to censoring. ${ }^{15}$

Table 6 reports our calculations. We see that the longevity of the speculative classes was substantially more enhanced than the longevity of the non-speculative classes. The non-speculative males are estimated to have lived between $5.65 \%$ and $9.06 \%$ longer than the Finlaison tables predicted. In contrast, the selected groups are estimated to have lived at least $20 \%$ and up to $122.91 \%$ longer. The non-speculative females appear even less selected than the males: their LEF is between $1.17 \%$ and $1.80 \%{ }^{16}$ These estimates are fully consistent with the graphical evidence in Figures 1 and 2.

\footnotetext{
${ }^{15}$ Formally, the upper bound LEF solves:

$$
N_{T} \cdot\left(A_{N}+\left(E\left[A_{F}\right]-A_{N}\right)(1+L E F)\right)=N_{D} \cdot A_{D}+N_{L} \cdot\left(A_{L}+\left(E\left[A_{L D} \mid \vec{l}\right]-A_{L}\right)(1+L E F)\right),
$$
}

where: $N_{T}, N_{D}$, and $N_{L}$ are the number of nominees, the number of nominees who had died by the time of observation, and the number of living nominees, respectively; $A_{N}, A_{D}$, and $A_{L}$ are the average ages of the nominees, the dead, and the "censored", respectively; and $E\left[A_{F}\right]$ and $E\left[A_{L D} \mid \vec{l}\right]$ are the expected average death age of the nominees and the expected average death age of the censored observations.

${ }^{16}$ The relative enhancements of the non-selected males and the non-selected females may stem from the combination of gender-blind early pricing and the fact that the pre-1828 data upon which the Finlaison tables were based did not distinguish between "speculative" and "non-speculative" nominees. The most profitable nominees under the pre-1829 pricing were the longer-lived females. Insofar as speculators in the pre-1829 period were aware of this, Finlaison's female life table is based on the mortality experience of a highly selected nominee pool. 


\section{Discussion and Conclusions}

Our analysis indicates that the market created by the U.K.'s 1808 Life Annuity Act was characterized by two types of adverse selection. The market displayed classic "self-selection," whereby annuitants purchasing annuities for themselves were longer lived than the average individual in the population. It also displayed "speculative selection," whereby pecuniary-minded individuals and institutions took advantage of an odd feature of the act and purchased annuities contingent on the lives of others.

The substantially stronger selection effects for speculator-nominated annuitants has important policy implications: it suggests particular caution when expanding "choice" in government provided services insofar as those choices can be made or influenced by individuals or institutions with primarily pecuniary motives.

The relative strength of speculative selection also has important implications for empirical research on insurance markets. In contrast to selfnominees, speculator nominated annuitants are unlikely to have been advantageously selected. The evidence for adverse selection among these nominees is therefore particularly compelling, relative to previous studies. Furthermore, the relative magnitudes of measured selection among speculative and non-speculative nominees - among whom advantageous selection was potentially problematic - lends credence to the view that advantageous selection may have substantial confounding effects in standard insurance markets. This is important for interpreting the underwhelming evidence of adverse selection in previous studies of contemporary insurance markets as well as for designing appropriate empirical approaches in future research.

\section{References}

[1] George Akerlof. The market for 'lemons': Quality uncertainty and the market mechanism. Quarterly Journal of Economics, 84(3):488-500, 1970 .

[2] Francis Baily. The Doctrine of Life-Annuities and Assurances. John Richardson, London, 1813. 
[3] Thomas Buchmueller and John DiNardo. Did community rating induce an adverse selection death spiral? Evidence from New York, Pennsylvania, and Connecticut. American Economic Review, 92:280-294, 2002.

[4] James Cardon and Igal Hendel. Asymmetric information in health insurance: Evidence from the national medical expenditure survey. $R A N D$ Journal of Economics, 32:408-427, 2001.

[5] John Cawley and Tomas Philipson. An empirical examination of information barriers to trade in insurance. American Economic Review, 89:827-846, 1999.

[6] Pierre-André Chiappori and Bernard Salanié. Testing for adverse selection in insurance markets. Journal of Political Economy, 108:56-78, 2000 .

[7] Alma Cohen and Liran Einav. Estimating risk preferences from deductible choice. American Economic Review, 97, 2007.

[8] Jacob Cohen. The elements of lottery in British government bonds, 1694-1919. Economica, 20, 1953.

[9] David Cutler, Amy Finkelstein, and Kathleen McGarry. Preference heterogeneity and insurance markets: Explaining a puzzle of insurance. American Economic Review Papers and Proceedings, 98(2):157162, 2008.

[10] David Cutler and Sarah Reber. Paying for health insurance: The tradeoff between competition and adverse selection. Quarterly Journal of Economics, 113:433-466, 1998.

[11] Thomas Davidoff, Jeffrey Brown, and Peter Diamond. Annuities and individual welfare. American Economic Review, 95:1573-1590, 2005.

[12] David de Meza and David Webb. Advantegeous selection in insurance markets. The RAND Journal of Economics, 32:249-262, 2001.

[13] Georges Dionne, Christian Gouriéroux, and Charles Vanasse. Testing for evidence of adverse selection in the automobile insurance market: A comment. Journal of Political Economy, 109:444-453, 2001. 
[14] William Farr. English Life Tables: Tables of Lifetimes, Annuities and Premiums. Longman, Green, Longman, Roberts and Green, London, 1864.

[15] Amy Finkelstein and James Poterba. Selection effects in the market for individual annuities: New evidence from the United Kingdom. Economic Journal, 112:28, 2002.

[16] Amy Finkelstein and James Poterba. Adverse selection in insurance markets: Policyholder evidence from the U.K. annuity market. Journal of Political Economy, 112:183-208, 2004.

[17] Amy Finkelstein and James Poterba. Testing for adverse selection with 'unused observables'. NBER Working Papers, 12112, 2006.

[18] Amy Finkelsten and Kathleen McGarry. Multiple dimensions of private information: Evidence from the long-term care insurance market. American Economic Review, 96:938-958, 2006.

[19] Alexander Glenn Finlaison. Tontines and life annuities. Republished in Rates of Mortality, B. Benjamin, ed., Gregg International Publishers Ltd., Germany 1973, 1860.

[20] John Finlaison. Report of John Finlaison. House of Commons Parliamentary Papers, March 31, 1829.

[21] John Francis. Annals, Anecdotes and Legends: A Chronicle of Life Assurance. Longman, Brown, Green and Longmans, London, 1853.

[22] Major Greenwood. English death rates, past, present and future: A valedictory address. Journal of the Royal Statistical Society, 99(4):674707, 1936.

[23] Frederick Hendriks. On the financial statistics of British government life annuities (1808-1855), and on the loss sustained by government in granting annuities. Journal of the Statistical Society of London, pages 325-384, 1856.

[24] Thomas McKeown and R. G. Record. Reasons for the decline of mortality in England and Wales during the nineteenth century. Population Studies, 16(2):94-122, 1962. 
[25] Olivia S. Mitchell, James M. Poterba, Mark Warshawski, and Jeffrey Brown. New evidence on the money's worth of individual annuities. American Economic Review, 89(5):1299-1318, 1999.

[26] Ray D. Murphy. Sale of annuities by governments. In Address at the Thirty-Third Annual Convention of The Association of Life Insurance Presidents, 1939.

[27] The Insurance Institute of London. The history of individual annuity contracts, 1969.

[28] Parliamentary Papers. Life annuities: Abstract and explanation of the act for enabling the commissioners for the reduction of the national debt to grant life annuities by the transfer of funded property. Hansard and Sons, 1808.

[29] Robert Pueltz and Arthur Snow. Evidence on adverse selection: Equilibrium signalling and cross subsidization in the insurance market. Journal of Political Economy, 102:236-257, 1994.

[30] A. Michael Spence. Job market signaling. Quarterly Journal of Economics, 87(3):355-374, 1973.

[31] Bertrand Villeneuve. Competition between insurers with superior information. European Economic Review, 49:321-340, 2003.

[32] David Weir. Tontines, public finance, and revolution in France and England, 1688-1789. Journal of Economic History, 49:95-124, 1989.

[33] E. A. Wrigley and R. S. Schofield. The Population History of England, 1541-1871: A reconstruction. Harvard University Press, 1981.

\section{Appendix}

This appendix shows that the test statistic $Z^{\prime}$, defined in Equation (3), has an asymptotic standard normal distribution.

Fix a mortality table $\vec{q}$ (suppressed for notational convenience henceforth). Then, fixing a class of nominees (e.g., pre 1829 males), view the random process underlying the data as a three-step compound process: (i) process $\alpha$ draws an independent random age and nomination year for each nominee $j=1, \cdots, N$ from some fixed distribution; (ii) 
process $\beta$ draws an independent random lifetime up to the censoring date for $j$ (using mortality table $\vec{q}$ ); and (iii) random process $\gamma$ draws an independent random lifetime beyond the censoring time for censored individuals. Note that our observations take place after processes $\alpha$ and $\beta$ (and before $\gamma$ ), but that we observe only aggregates associated with these processes.

Let $m_{j}$ denote the (random) death age of $j$. Define $b\left(\alpha_{j}, \beta_{j}\right)=E_{\gamma}\left[m_{j} \mid \alpha_{j}, \beta_{j}\right]$ and $a\left(\alpha_{j}\right)=E_{\beta, \gamma}\left[m_{j} \mid \alpha_{j}\right]$. Then:

$$
\begin{aligned}
E\left[\bar{d} \mid \overrightarrow{d^{\text {early }}}, \vec{l}\right]-E[\bar{d} \mid \vec{e}] & =E\left[\bar{d} \mid\left\{\alpha_{j}, \beta_{j}\right\}_{j=1}^{N}\right]-E\left[\bar{d} \mid\left\{\alpha_{j}\right\}_{j=1}^{N}\right] \\
& =\frac{1}{N} \sum_{j=1}^{N}\left(b\left(\alpha_{j}, \beta_{j}\right)-a\left(\alpha_{j}\right)\right) .
\end{aligned}
$$

Since $b\left(\alpha_{j}, \beta_{j}\right)-a\left(\alpha_{j}\right), j=1, \cdots, N$ are i.i.d. random variables, we drop the subscript $j$ and note that:

$$
Z^{\prime} \equiv \frac{E\left[\bar{d} \mid \overrightarrow{d^{\text {early }}}, \vec{l}\right]-E[\bar{d} \mid \vec{e}]}{\sqrt{V_{\alpha, \beta}[b(\alpha, \beta)-a(\alpha)] / N}}
$$

has an asymptotic standard normal distribution by the Central Limit Theorem.

Towards deriving the variance of $b(\alpha, \beta)-a(\alpha)$, note that:

$$
\begin{aligned}
V_{\alpha, \beta, \gamma}[m] & =E_{\alpha, \beta, \gamma}\left[m^{2}\right]-\left(E_{\alpha, \beta, \gamma}[m]\right)^{2} \\
& =E_{\alpha, \beta}\left[V_{\gamma}[m \mid \alpha, \beta]+\left(E_{\gamma}[m \mid \alpha, \beta]\right)^{2}\right]-\left(E_{\alpha, \beta}\left[E_{\gamma}[m \mid \alpha, \beta]\right]\right)^{2} \\
& =E_{\alpha, \beta}\left[V_{\gamma}[m \mid \alpha, \beta]\right]+E_{\alpha, \beta}\left[(b(\alpha, \beta))^{2}\right]-\left(E_{\alpha, \beta}[b(\alpha, \beta)]\right)^{2} \\
& =E_{\alpha, \beta}\left[V_{\gamma}[m \mid \alpha, \beta]\right]+V_{\alpha, \beta}[b(\alpha, \beta)],
\end{aligned}
$$

where we have used the law of iterated expectations, and where we explicitly subscript the variance terms with the random process(es) causing the variation. Similar logic yields:

$$
V_{\alpha, \beta, \gamma}[m]=E_{\alpha}\left[V_{\beta, \gamma}[m \mid \alpha]\right]+V_{\alpha}[a(\alpha)] .
$$

Since $\operatorname{Cov}_{\alpha, \beta}[b(\alpha, \beta), a(\alpha)]=V_{\alpha}[a(\alpha)]$, we also have:

$$
\begin{aligned}
V_{\alpha, \beta}[b(\alpha, \beta)-a(\alpha)] & =V_{\alpha, \beta}[b(\alpha, \beta)]-V_{\alpha}[a(\alpha)] \\
& =E_{\alpha}\left[V_{\beta, \gamma}[m \mid \alpha]\right]-E_{\alpha, \beta}\left[V_{\gamma}[m \mid \alpha, \beta]\right],
\end{aligned}
$$

where the last equality uses Equations (8) and (9).

To complete our derivation, observe that

$$
N V_{\beta, \gamma}[\bar{d} \mid \vec{e}]=N V_{\beta, \gamma}\left[\bar{d} \mid\left\{\alpha_{j}\right\}_{j=1}^{N}\right]=\frac{1}{N} \sum_{j} V_{\beta, \gamma}\left[m_{j} \mid \alpha_{j}\right] \rightarrow_{p} E_{\alpha}\left[V_{\beta, \gamma}[m \mid \alpha]\right]
$$

Similarly,

$$
N V_{\gamma}\left[\vec{d} \mid \overrightarrow{d^{e a r l y}}, \vec{l}\right]=N V_{\gamma}\left[\bar{d} \mid\left\{\alpha_{j}, \beta_{j}\right\}_{j=1}^{N}\right]=\frac{1}{N} \sum_{j} V_{\gamma}\left[m_{j} \mid \alpha_{j}, \beta_{j}\right] \rightarrow_{p} E_{\alpha, \beta}\left[V_{\gamma}[m \mid \alpha, \beta]\right] .
$$

The asymptotic standard normality of $Z^{\prime}$ in Equation (3) follows directly from these observations and Equations (7) and (10). 